\title{
Uma revisão integrativa sobre a rede de apoio social de adolescentes vítimas de violência
}

\author{
An integrative review of the social support network for adolescents victims of violence
}

\author{
Gabriella Santos Ramalho ${ }^{1}$, Ilanna Pinheiro da C. Medeiros $^{2}$, , Ana Cláudia de Azevedo Peixoto ${ }^{3}$
}

Como citar esse artigo. RAMALHO, G. S; MEDEIROS, I. P. C; PEIXOTO, A. C. A. Uma revisão integrativa sobre a rede de apoio social de adolescentes vítimas de violência. Mosaico - Revista Multidisciplinar de Humanidades, Vassouras, v. 12, n. 3, p. xx-xx, set./ dez. 2021.

Nota da Editora. Os artigos publicados na Revista Mosaico são de responsabilidade de seus autores. As informações neles contidas, bem como as opiniões emitidas, não representam pontos de vista da Universidade de Vassouras ou de suas Revistas.

\author{
Resumo
}

A Rede de apoio social pode ser definida como a construção de relações de apego e vínculos da criança e do adolescente. Quando referente à crianças e adolescentes institucionalizadas, a rede de apoio pode ser um fator de proteção que minimiza consequências negativas referentes ao processo de institucionalização nessa fase da vida. O objetivo deste artigo é apresentar e discutir a compreensão de pesquisas que abordam a formação da rede de apoio social para adolescentes vítimas de violência. Para isto, fez-se uso da Revisão Integrativa de Literatura e através das bases de dados Lilacs, Scielo, Pepsic e BVS, foram analisados artigos dentro da temática nos últimos dez anos, de 2009 a 2019, todos em língua portuguesa. Após análise foi possível levantar as lacunas na atuação da rede de apoio social assistencial e também socioafetiva; observou-se também necessidades quanto ao trabalho interdisciplinar. Os artigos analisados elucidaram propostas para melhor eficácia do trabalho em rede, a partir de intervenções em níveis primários, com diálogos com a comunidade, escolas e famílias; bem como um olhar transdisciplinar dos equipamentos no que se refere as famílias em situação de violência, capacitação dos profissionais para melhor abarcar a temática, e uma organização dos serviços, visando uma melhor comunicação entre as redes protetivas.

Palavras-chave: Rede de apoio social; Adolescente; Violência; Revisão Integrativa.

\begin{abstract}
The social support network can be defined as the construction of attachment relationships and bonds of children and adolescents. When it comes to institutionalized children and adolescents, the support network can be a protective factor that minimizes negative consequences related to the institutionalization process at this stage of life. The objective of this article is to present and discuss the understanding of research that addresses the formation of the social support network for adolescent victims of violence. For this, the Integrative Literature Review was used and through the Lilacs, Scielo, Pepsic and VHL databases, articles within the subject in the last ten years, from 2009 to 2019, all in Portuguese, were analyzed. After analysis, it was possible to raise the gaps in the performance of the social assistance and also socio-affective support network; there were also needs regarding interdisciplinary work. The articles analyzed elucidated proposals for better effectiveness of network work, from interventions at primary levels, with dialogues with the community, schools and families; as well as a transdisciplinary look at equipment with regard to families in situations of violence, training of professionals to better cover the theme, and an organization of services, aiming at better communication between protection protection networks.
\end{abstract}

Keywords: Integrative Review; Adolescents; Violence; Social support network.

\section{Introdução}

Segundo os estudos de Antoni e Koller (2010) ao embasarem-se nas pesquisas de Belsky (1993) e Bronfenbrenner (2004), a violência vista nos ambientes familiares tende a ser fruto de um contexto histórico, contemporâneo e cultural, com explicações que transpassam as características particulares das famílias e sujeitos. Para melhor compreensão do fenômeno da violência, visto como um problema de saúde pública, é preciso perceber diversos aspectos, como a pessoa, o processo, o contexto e o tempo. Por pessoa, entende-se o sujeito ou o grupo com características biopsicossociais; já o processo se dá nas experiências e interpretações do ambiente, com desempenho de papéis e dinâmica familiar; o aspecto contexto abarca o espaço social em que as histórias dos sujeitos ou grupos, como a família, se desenvolve; e o tempo refere-se às marcas culturais e históricas construídas na sociedade, seus rituais, heranças e demais influências perpassadas em uma época. $\mathrm{O}$ fenômeno da violência perpassa estes processos, estando presente não somente no indivíduo.

O Fundo Internacional das Nações Unidas (UNICEF) apresentou dados sobre a violência e o seu impacto no desenvolvimento infantil e pondera que, a partir dos estudos sobre violência estrutural, é possível observar de modo complexo as formas de violência que ocorrem nas comunidades, sejam essas familiares,

Afiliação dos autores

${ }^{1}$ Mestranda da Universidade Federal Rural do Rio de Janeiro, pesquisadora do Laboratório de Estudos sobre Violência contra Crianças e Adolescentes (LEVICA)

${ }^{2}$ Doutoranda da Universidade Federal Rural do Rio de Janeiro, pesquisadora do Laboratório de Estudos sobre Violência contra Crianças e Adolescentes (LEVICA)

${ }^{3}$ Professora Doutora do departamento de psicologia da Universidade Federal Rural do Rio de Janeiro, coordenadora do Laboratório de Estudos sobre Violência contra Crianças e Adolescentes (LEVICA).

* Email de correspondência: psicologa.gabriellarj@gmail.com 
institucionais ou comunitárias. Como uma base que norteia as relações estabelecidas e as demais práticas de violência, a violência estrutural explica, por exemplo, a prática comum de violência física e psicológica como forma de educação como característica cultural, além de permitir com que a criança e o adolescente sejam vítimas diretas da violência, e também testemunhas de diversas violações, o que acarreta prejuízo no desenvolvimento (UNICEF, 2015).

Por violência estrutural entende-se, segundo Neto e Moreira (1999), uma forma de violência naturalizada em nossa cultura, muitas vezes, não debatida nas nossas relações e vida cotidiana, embora inflija diretamente a vida de muitos grupos sociais. Os autores apontam que tal violência reflete uma relação de poder e dominação do Estado e de alguns grupos sociais de domínio socioeconômico e que, no senso comum, pode ser vista como uma situação de insuficiência das ações do Governo. A violência estrutural, assim, se dá quando há privação de acesso a direito básicos dos sujeitos, como alimentação, saúde, moradia, educação, quando as políticas públicas não alcançam parcelas significativas da população, não permitindo direitos fundamentais para qualidade de vida e, provocando assim, exclusões sociais. Segundo esses autores, a violência estrutural remete a uma escolha, preferência de direitos para camadas consideradas privilegiadas da população, em detrimentos de muitos (NETO; MOREIRA, 1999).

Segundo Eloy (2014), em casos de violência intrafamiliar, a criança é capaz de sofrer danos que vão desde a agressão física à humilhação, constrangimento e rejeição. E os castigos físicos dados como formas de educação e disciplina infelizmente são uma prática que se faz presente ao longo de gerações, e ainda hoje é utilizada como forma de educação, prática comum dentro do senso comum. Para os cuidadores que, por sua vez, também foram vítimas de violência, se torna um desafio educar sem a agressão física e psicológica e romper com ideias as quais acreditavam ser positivas para criação, principalmente por terem sido frutos de uma educação em que se utilizava métodos punitivos nas relações.

Segundo Cecconello et al. (2003), os ambientes familiares, onde se deveria ter sensações de proteção e garantia de direitos, são, muitas vezes, locais de vivência de comportamentos violentos, atrelados ainda como prática educativa. Diante disso, podemos pensar as configurações de apego e vínculo, os quais Mayer e Koller (2012) discutem, a partir da teoria do desenvolvimento de Bronfenbrenner (1979/1996). As autoras explicam que o apego seguro é a base da sensação de estabilidade e reciprocidade, e permite o desenvolvimento estável dos relacionamentos da criança, sendo importante para seu senso de apoio.

Apego seguro pode serentendido como um modelo para o estabelecimento de relações que são consideradas saudáveis ou funcionais. Observando o sujeito como um todo, a abordagem bioecológica do desenvolvimento humano, compreende o ser humano em uma totalidade, atravessando questões biológicas, mas também sociais, relacionais, ambientais e subjetivas. Nesse sentido, as relações têm um impacto no desenvolvimento humano, seja de modo positivo ou negativo. Ao interagir com o meio e ser influenciado por esse, o sujeito pode, por exemplo, se ver em uma situação de risco, como as encontrada nas situações que envolvem a violência em suas relações (HABIGZANG, et al., 2012).

Assim, as vivências de violência influenciam diretamente na formação conflituosa na fase da formação do apego, gerando um vínculo inseguro entre as crianças e seus cuidadores. As autoras dissertam ainda que o que a rede de apoio social e a representação mental de apego revelam e que se faz necessário estudar o apoio social em crianças em situações consideradas de risco para melhor compreender e abrandar os riscos nos quais as crianças, e também adolescentes, são submetidos (HABIGZANG, et al., 2012).

\section{Referencial teórico}

Segundo o Estatuto da Criança e do Adolescente (ECA), no art.04, "É dever da família, da comunidade, da sociedade em geral e do poder público assegurar, com absoluta prioridade, a efetivação dos direitos referentes à vida, à saúde, à alimentação, à educação, ao esporte, ao lazer, à profissionalização, à cultura, à dignidade, ao respeito, à liberdade e à convivência familiar e comunitária" (BRASIL, 1990). E, conforme compreende o ECA, em casos de violação de direitos de crianças e adolescente, equipamentos de proteção precisam ser acionados, pensando no melhor interesse da criança e na política de proteção integral.

Muito se avançou em políticas públicas para garantia de direitos e proteção de crianças e adolescentes no Brasil e, entre muitas medidas, a comunidade e a família, que apontam para os laços e redes sociais, se colocam como agentes protetores, juntamente com a ação legal e governamental. Mas foi pensando em medidas de proteção legais que o ECA (BRASIL, 1990) ponderou o princípio da proteção integral, que ordena a realização de denúncias sobre maus-tratos, suspeitos ou confirmados. Tais notificações se colocam como medidas protetivas, e é dever dos profissionais e instituições também agirem do modo protetivo nesses casos (FERREIRA; SHRAMM, 2000).

Como uma das medidas protetivas possíveis, ressalta-se a rede de apoio social. Esta pode ser compreendida através de figuras de apego e vínculos da criança e do adolescente, que se estabelecem ao longo de suas vidas. É a rede de apoio que garante satisfação e 
estabilidade e, sendo um apoio socioafetivo, se constitui nas relações de maior proximidade do sujeito. Avalia-se, assim, a estrutura e a funcionalidade da rede, verificando os núcleos relacionais da criança e do adolescente e se esses espaços têm sido uma rede de apoio social ou se há propagação da violência (GARMEZY; MASTEN, 1994 apud MAYER, 2002). Colaborando com essa ideia, Mayer e Koller (2012) também colocam que fatores de proteção podem abrandar o impacto de situações de risco e permitir comportamentos adaptativos do sujeito, possibilidades de enfrentamento e resiliência.

Segundo o UNICEF (2015), existem alguns fatores que contribuem para a vulnerabilidade às violências intrafamiliares e, dentre esses fatores, destacam-se as relações parentais rígidas, histórico de violência familiar e a ausência de uma rede de apoio. Em consonância a esta descrição, os estudos de Siqueira et al. (2006) revelam que fatores de risco dentro do ambiente familiar, como a violência, podem provocar sensação de vulnerabilidade dos membros.

O Ministério da Saúde (2010) foca em problemas como abuso de substâncias, envolvimento precoce com atividade sexual, ansiedade, transtornos depressivos, presença de alucinações, comportamento agressivo e baixo rendimento escolar, além de tentativas de suicídio. Além disso, pode ocorrer alteração no desenvolvimento típico físico e cognitivo, além de, em casos de violência sexual, adoecimentos e outros complicadores, como gravidez precoce, doenças sexualmente transmissíveis e outros.

Segundo os estudos de Habigzang, et al. (2012), quando a violência é considerada intrafamiliar, as consequências na vida da criança e do adolescente são de maior impacto, visto que esses podem confundir uma relação afetuosa e amorosa com violência e comportamentos abusivos, atrelando amor a agressão e também introjetando-se modelos disfuncionais que certamente serão utilizados em elações futuras. Desse modo, uma relação parental pode ser, em muitos casos, um auxílio e um amparo diante de situações conflituosas, mas, em tantos outros, pode ser uma relação causadora de violência. Acrescido a isso, Habigzang, Koller, Azevedo (2005) revelam que crianças e adolescentes se tornam vulneráveis em meio a fatores de risco e, quando não há uma rede de apoio social e afetiva, há uma maior possibilidade de estarem propensos à psicopatologias $\mathrm{e}$ comportamentos não adaptativos.

Diante do quadro de violência, uma das medidas protetivas possíveis com crianças e adolescentes está no direcionamento para Casas de Acolhimento, caso não haja possibilidade de inserção na família extensa. Sobre isso, Siqueira et al. (2012) declaram que é muito comum a estadia prolongada de adolescentes, ainda que se descumpram os princípios do ECA, permanecendo sem possibilidade de reinserção familiar ou de entrada em famílias substitutivas. Khattar (2019) explica ainda que tais crianças e adolescentes não podem ser descritas como órfãos, visto que existem possibilidades de família extensa, e questiona ainda a necessidade de se pensar a rede comunitária dessas crianças e adolescentes.

Neste trabalho buscou-se compreender como as pesquisas têm discutido o tema da formação da rede de apoio social para adolescentes vítimas de violência através do método da Revisão Integrativa de Literatura, a qual procura responder como as pesquisas têm se posiciobado quanto a rede de apoio social de adolescentes vítimas de violência.

\section{Método}

A Revisão Integrativa da Literatura, segundo Souza et al. (2010) consiste em um método que faz um levantamento amplo de estudos, sejam estes experimentais ou não, e que permite um conhecimento mais completo do assunto que se propõe analisar. Segundo um documento sobre formas de revisões da Unesp (2015), a Revisão Integrativa é um método rigoroso e de análise ampla, que combina diversos estudos e metodologias e integra seus resultados, definindo conceitos e lacunas nas pesquisas e áreas de conhecimento, permitindo um saber mais específico ao analisar pesquisas anteriores dentro da temática escolhida.

Para construção da Revisão Integrativa da Literatura, foi preciso identificar o tema e pontuar hipóteses para a confecção da pesquisa. Para isso, foram utilizadas palavras chaves para procura dos materiais, com um viés amplo da pesquisa, a fim de verificar diversas contribuições dentro da temática. As palavras chaves elaboradas foram: [vínculo e adolescência], [suporte social e adolescente], [rede de apoio social e adolescência], [violência e adolescente], [fatores de proteção e adolescência], [relações e prevenção de violência], [fatores de proteção e violência], utilizadas em conjunto ou isoladamente.

Os critérios de inclusão e exclusão foram observados a fim de traçar a busca na literatura de modo mais objetivo e delimitado. Critérios de inclusão foram artigos que estivessem sido publicados somente na língua portuguesa e com tempo de publicação dentro dos últimos dez anos. Para isso, a internet foi um recurso para pesquisa, através dos acervos eletrônicos. Os escritos acadêmicos descritos foram escolhidos manualmente, através dos bancos de dados eletrônicos: Lilacs, Scielo, Pepsic e na BVS. Juntamente com o critério de inclusão e exclusão, os textos foram selecionados, lidos e analisados.

$\mathrm{Na}$ etapa seguinte foi preciso definir quais informações seriam pesquisadas e categorizadas, ponderando a confiabilidade dos estudos. Após esse momento, foi necessário avaliar os estudos já colhidos 
e inclusos na pesquisa, com análise crítica e explicativa dos estudos analisados, verificando diferenças e semelhanças, de modo imparcial. A próxima etapa foi a interpretação dos dados apresentados, comparando as considerações e sugestões, sendo possível realizar indicações e pareceres. A última etapa, por fim, foi realizar uma apresentação em síntese de toda análise e seus resultados (UNESP, 2015).

\section{Resultados e discussão}

Após a aplicação do método, foram encontrados um total de 350 artigos nas plataformas analisadas. Sendo 110 na plataforma Scielo, 77 na LILACS, 158 na BVC e

5 na plataforma PEPSIC, a partir dos descritores previamente selecionados. Permanecendo somente os textos em língua portuguesa, o número total foi de 247 textos. Conforme os índices de exclusão, foram excluídos 22 documentos por serem teses de conclusão de curso ou pós graduação; 25 foram excluídos por terem mais de 10 anos de publicação e também por não estarem disponíveis na íntegra.

Restaram, assim, 200 artigos. $\mathrm{Na}$ exclusão por título, 74 artigos foram excluídos e, com a exclusão por textos repetidos e por resumo foram deletados, respectivamente, 54 e 54 artigos. A partir da exclusão por assunto, 10 artigos foram descartados, permanecendo 8 artigos para análise. Tal procedimento é ilustrado na figura $01 \mathrm{em}$ anexo. Importante ressaltar que o descritor [violência e adolescente] foi alterado para [violência e adolescência] quando não encontrado nenhum resultado. Na tabela 01 constam os autores, nome do artigo, revista de publicação, ano, tipo da pesquisa, instrumentos e participantes.

A tabela 01 foi organizada de modo a conter os tipos de pesquisa, instrumentos e a forma de violência discutida. Dos 8 artigos, 5 apresentam uma abordagem qualitativa; 2 de abordagem quantitativa e 1 de abordagem quantitativa-qualitativa. Quanto aos instrumentos, prevaleceu a entrevista semiestruturada em 5 textos, questionário fechado em 2 textos - os mesmos quantitativos, e grupos focais e escala CADRI (Certificado de Movimentação de Resíduos de Interesse Ambiental) no texto de abordagem quantitativaqualitativa. Quanto à violência discutida nos textos, estão presentes violência afetivo- sexual, violência doméstica; física e psicológica; violência sexual e violência de modo não especificada.

Quanto ao público-alvo das pesquisas analisadas, percebe-se uma ênfase na rede assistencial, seja na atenção primária ou nas equipes de assistência especializada, presentes nos 5 artigos de abordagem qualitativa. Os dois artigos de cunho quantitativo tiveram como público-alvo os próprios adolescentes, estudantes e o artigo de abordagem mista também focalizaram os adolescentes.

A partir da análise dos artigos, foi possível notar alguns pontos em comum nas discussões, como a rede de apoio em nível assistencial e suas faltas; a lacunas da rede de apoio socioafetiva e as possibilidades e propostas de fortalecimento e melhoria da rede de apoio social como um todo, que serão discutidos a seguir.

\section{Das faltas da rede de apoio assistencial para casos de adolescentes vítimas de violência}

A partir das perspectivas de profissionais da atenção básica e de familiares que pertencem ao território pesquisado, Carlos et al. (2016) compreendem as redes de cuidado e a atuação da equipe diante de casos de violência. Os autores apontam para uma rede com lacunas no que diz respeito aos vínculos com instituições, estando muitas vezes ausentes. Apresentam que os profissionais da assistência social creditam que a política de assistência é pouco clara, pois relatam não entendimento da atuação como um todo dos diferentes profisionais, relatando ser confusa a estruturação da assistência e não compreendendo a ação ou efetividade dos demais equipamentos.

Ademais, os autores citam que "o número de entidades privadas no setor da assistência social é significativamente maior que o de entidades estatais" (CARLOS, et al., 2016) e, nessas estruturas, há formas de trabalho diferentes do que são vivenciados pelos espaços estatais. Ao afirmarem isso, correlacionam com as vulnerabilidades de organização e de entendimetno sobre o setor da assistência social.

Os autores revelam uma lógica de fragmentação da rede de assistência, que prejudica o acolhimento qualificado e corrobora para que as famílias fiquem "submetidas à diversas ações atomizadas, muitas vezes levando à não interrupção do ciclo da violência" (CARLOS et al., 2016, p. 7). As famílias entrevistadas na pesquisa pontuam ainda que as ONGs são fontes de rede de apoio social, seja em um papel informativo ou de auxílio material, que se coloca como rede de assistência.

A mesma pesquisa discorre sobre as dificuldades de interlocução entre as instâncias da saúde e educação, o que prejudica a atenção qualificada em casos de violência contra adolescentes. Os profissionais entrevistados na pesquisa revelam que o trabalho em parceria não era eficiente entre saúde-educação, e os familiares relataram que sentem o vínculo entre os mesmos e as escolas de seus filhos como "fragilizado, em especial pela falta de reciprocidade nas informações ou ações desenvolvidas" (CARLOS et al., 2016, p. 7). De modo geral, tanto 
profissionais da ABS (Atenção Básica em Saúde) quanto familiares, discerniram uma rede fragilizada, com poucos vínculos importantes, apontando para uma necessidade de políticas públicas em prol do empoderamento familiar e comunitário, com mais autonomia das famílias e cuidado interdependente.

Ribeiro e Leite (2018) também corroboram para o entendimento sobre as redes de apoio, indicando um serviço pueril no combate à violência contra crianças e adolescentes, apontando falta de recursos de professores e equipes pedagógicas, no âmbito educacional, e conselheiros tutelares e demais profissionais da saúde, o que permite que haja constrangimentos sobre o cuidado recebido pelos usuários, além de falta de preparo profissional para uma escuta qualificada, tempo reduzido para dar atenção às famílias, dificuldades burocráticas, que se interpõem entre a família e as possibilidades de cuidado das redes apresentadas. Indicaram também que o tempo e a lógica de trabalho fragilizam o período de investigação das famílias, pautando principalmente uma lógica de encaminhamentos, diminuindo a eficácia dos recursos. Além de dificuldades de comunicação entre os equipamentos, proporcionando uma rede que não se sustenta.

Gonçalves et al. (2015), ao estudarem a percepção da equipe de saúde sobre o papel da rede em casos de violência contra adolescentes, verificaram que o serviço social atua de modo fundamental para o trabalho em rede, mas que, ainda assim, apresenta dificuldades e insuficiências, principalmente no que tange ao fluxo de atendimento e normatização do trabalho. A saúde é o setor principal para a recepção dos casos de violência e encaminhamento para a atenção especializada ou a assistência social. Os autores afirmaram ainda que se faz necessário cada vez mais o cuidado do poder público em casos de violência como um problema de saúde pública. As entrevistas realizadas por tais pesquisadores visaram investigar como os profissionais da assistência percebiam o trabalho em rede e como ocorriam os atendimentos. Os mesmos declararam faltas em relação à normatização e dificuldades no fluxo de atendimentos, que se colocam como obstáculos para um atendimento de qualidade. Também apontaram desqualificação profissional, necessidade de capacitação para atendimento à crianças e adolescentes para compreensão das demandas sociais.

Acrescido a isso, Melo et al. (2017) investigaram como graduandos de enfermagem percebem sua atuação como assistência e rede de proteção diante de casos de violência, compreendendo que muitas vezes a enfermagem é a porta de entrada de cuidado e de denúncias sobre a violência. Através de entrevistas semiestruturadas, os autores procuraram entender como estes estudantes atuavam em rede diante da violência. Os autores indicaram escassez de preparação profissional para lidar com casos de violência, desarticulação da equipe e necessidade de que os futuros enfermeiros tenham um olhar sensível às demandas emocionais e relacionais dos pacientes, para além de questões físicas atendidas. De modo geral, os entrevistados da pesquisa apontaram falhas na capacitação profissional, bem como na organização dos serviços de saúde. Tais faltas influenciam diretamente a capacidade de discernir sobre a violência e poder confirmá-la, até mesmo para realização da denúncia. Quanto a isto, alguns entrevistados acreditam não ser uma responsabilidade deles, limitando-se ao cuidado físico e encaminhamentos, inferindo mais uma vez sobre as faltas na capacitação.

Faraj e Ciqueira (2012) também entrevistaram profissionais do CREAS (Centro de Referência Especializado de Assistência Social) para entender a rede de proteção à criança e adolescente vítima de violência em um município do Rio Grande de Sul. Em sua pesquisa, as mesmas faltas e lacunas apontadas pelas demais pesquisas foram apresentadas. Também revelaram falta de capacitação dos profissionais para o acolhimento e também para prevenção em rede com demais instâncias como escolas, por exemplo, além de fragmentação de comunicação na rede. Os entrevistados reafirmaram a importância social do CREAS e de equipamentos especializados em atendimentos de violência, mas ainda descreveram fragilidades nas estruturas físicas, falta de informatização, materiais como testes psicológicos e meios de locomoção para visitas, até mesmo faltas de telefones no CREAS para contato com os usuários, acrescido de grande demanda de atendimentos.

Compreendendo essa perspectiva, Teixeira-filho et al. (2013,p.90) comentaram que "a maioria das vítimas finda por relatar o ocorrido aos amigos e responsáveis, mas pouco ou nada é feito, em termos de medidas protetivas a elas", eludindo ao fato de que o silêncio nem sempre é quebrado e, quando ocorre, faltam medidas protetivas. Dos 110 pesquisados, $52 \%$ descreveram que nada foi feito e, dos cuidados que foram tomados, pontuam encaminhamento à Justiça somente em 21.2\% dos casos e $15.1 \%$ foram encaminhados às equipes de saúde. Tais dados esclarecem a dificuldade dos casos serem encaminhados para equipes de assistência e, em muitos casos, a ausência de rede de apoio.

Soares et al. (2013) analisaram a rede de apoio de adolescentes que foram vítimas de violências afetivosexuais e os resultados indicaram que somente 5\% dos entrevistados, de um total de 283 adolescentes, solicitaram apoio. Sua fonte de acolhimento e proteção foram amigos e familiares, enquanto profissionais de saúde quase não foram citados como fontes de apoio, totalizando $12,1 \%$ dos casos. Os autores citam ainda outro estudo semelhante realizado em dez capitais do Brasil, no qual amigos e familiares ocupavam as maiores posições quanto à rede de apoio, enquanto profissionais religiosos e profissionais de saúde, bemcomo professores, 
eram pouco citados. Os professores totalizaram somente $2,6 \%$ dos casos, enquanto profissionais de saúde e religiosos ocuparam, respectivamente, $3,3 \%$ e 3,6\%. Torna-se perceptível, assim, as lacunas da rede de apoio social pela assistência e equipamentos de saúde.

\section{Lacunas da rede socioafetiva na vida de adolescentes vítimas de violência}

Quanto às redes de apoio socioafetivas pesquisadas nos artigos aqui analisados, Carlos et al. (2016) apontam que, das famílias analisadas por eles, atendidas por ABS de um município do interior de São Paulo, havia um padrão de uma rede mediana, com poucos laços afetivos ou significativos que, quando existiam, se apresentavam de modo fragilizado. Em um dos mapas de rede de apoio apresentados pelos pesquisadores, havia somente 4 vínculos significativos e um desses era a família. A precariedade dos vínculos segue-se em outros mapas apresentados, indicando dois vínculos considerados importantes e, ainda que fossem próximos no que tange a localidade, eram afetivamente distantes. A pesquisa apontou que os familiares também se constituíam como uma rede frágil e precária, até mesmo inexistente. Os entrevistados relataram ainda que, diante da violência sofrida, não tinham ninguém para contar, para lhes prestar suporte.

Na pesquisa realizada por Paludo e Schirò (2012) a respeito da violência sexual contra adolescentes e jovens brasileiros, cuja participação contou com 7316 pessoas, entre 14 e 24 anos, notou-se que "o apoio familiar diminui em $41,3 \%$ a chance de o adolescente/ jovem sofrer algum tipo de violência sexual na sua família" (PALUDO; SCHIRÒ, 2012, p. 400). Dentre os resultados das autoras, comparando o modelo de violência sexual acometida pela família e na comunidade, revelam que

A percepção de apoio familiar foi a única variável que se revelou como protetora, face à violência sexual, em ambos os modelos, sugerindo que a qualidade das relações familiares toma especial importância na vida de crianças e jovens (PALUDO; SCHIRÒ, 2012, p. 400).

Teixeira-Filho et al. (2013) descrevem que, de 236 adolescentes pesquisados, a maioria procurou ajuda de amigos e responsáveis, mas nada ou quase nada foi feito como medida protetiva. Em concordância, Soares et al. (2013, p. 1121) revelam que, de 283 adolescentes de 15 a 19 anos, "apenas $5 \%$ dos adolescentes solicitaram ajuda para problemas decorrentes de violência e, quando o fizeram, procuraram principalmente amigos e familiares"

\section{Rede interdisciplinar para um trabalho efetivo e protetivo quanto a violência na infância e adolescência}

Sobre a interdisciplinaridade no combate e prevenção da violência, Carlos et al. (2016, p.8) dissertaram sobre a necessidade de olhar o fenômeno da violência de modo multidimensional, compreendendo os diferentes fatores que podem ser percebidos dentro deste tema. Revelaram ainda a necessidade de se trabalhar em rede, com múltiplos olhares de assistência, para um cuidado mais efetivo. Para isso, pautaram-se no trabalho do "paradigma da complexidade", com necessidade de contextualizar o fenômeno da violência. Ratificaram que estudos recentes reforçam a importância da articulação de programas e setores para reduzir a vulnerabilidade de grupos populacionais, particularmente de crianças e adolescentes, e reconhecem suas habilidades, talentos e capacidade criativa para a (re)criação de diversas realidades.

Ribeiro e Leite (2018) compreenderam que existem relações que atuam de modo dinâmico na vida dos sujeitos, assim como crianças e adolescentes, e essa vivência multifocal necessita de um olhar múltiplo em abordagem para perceber cada detalhe que envolve a violência. Gonçalves et al. (2015) ratificam essa ideia ao apresentarem o SUS (Sistema Único de Saúde) e a necessidade de se trabalhar em rede para proteção de crianças e adolescentes vítimas de violência.

Entendendo o SUS como uma estrutura integrada, pautada em políticas públicas e de ação coletiva, é fundamental que os profissionais que atuam frente ao SUS compreendam que todo o trabalho depende de uma ação integrada, assim como o enfrentamento da violência "requer uma intervenção intersetorial e interdisciplinar, extrapolando os limites do setor da saúde" (GONÇALVES et al., 2015, p. 979). Os autores entenderam que esse trabalho em rede é capaz de fortalecer o apoio e a proteção de crianças e adolescentes frente a temática da violência.

Melo et al. (2017) argumentaram através do setor da saúde, mais especificamente do setor da enfermagem, que a assistência aos casos, de modo geral, deve ser integral e visando também a prevenção. Quanto ao cuidado específico da enfermagem, os autores pontuaram a necessidade de enfermeiros entenderem o seu papel na rede com o encaminhamento das suspeitas e também de denúncias, pensando no rompimento do ciclo de violência. Acrescentando ao debate, Faraj e Siqueira (2012), observando o funcionamento do CREAS, reafirmaram a necessidade de um trabalho articulado para uma prestação de serviço qualificada no que tange à violência contra crianças e adolescentes.

\section{Possibilidades e propostas de fortalecimento e melhoria da rede de apoio social}

Como propostas apresentadas pelos autores 
analisados nessa revisão integrativa para a melhoria da rede de apoio social, Carlos et al. (2016) argumentaram que, no caso da enfermagem e a área da saúde como um todo, é possível atuar de modo a reafirmar e fortalecer debates e um olhar transdisciplinar para famílias envolvidas na temática da violência. Os autores também pontuaram as intervenções em nível primário e secundário como potencialidades para o enfrentamento da violência. Indo ao encontro dessa ideia, Ribeiro e Leite (2018) descreveram a necessidade de capacitar profissionais para a identificação e notificação da violência, assim como também reafirmaram Gonçalves et al. (2015) e Melo et al. (2017). Estes últimos ainda ponderaram uma melhor organização dos serviços para prestar um atendimento qualificado aos usuários.

Além disso, Ribeiro e Leite (2018) também ressaltaram como fundamental a comunicação entre as redes de proteção, para o que o apoio seja efetivo. Para tal, os mesmos apontam alguns caminhos possíveis, como reorganizar fluxos, facilitar os encaminhamentos e subsidiar contínua formação das equipes técnicas, que seriam, de acordo com os autores, caminhos possíveis e de baixo custo, necessitando tão somente de uma mudança na lógica estrutural daqueles que põe em prática as políticas públicas a fim de flexibilizar burocracias e tornar a proteção mais efetiva em todos os âmbitos (OLIVEIRA, et al., 2006 apud RIBEIRO; LEITE, 2018).

Outra medida que se faz necessária é reafirmar o espaço das escolas públicas enquanto agentes de proteção da infância e adolescência, com promoção dos seus direitos, sendo imprescindível um exercício de atenção dos profissionais das escolas para o fenômeno da violência e preservação de direitos, segundo Teixeirafilho et al., 2013. Na pesquisa dos autores, houve pequena procura dos adolescentes que foram vítimas de violência sexual a seus professores para revelar o abuso. Entretanto, o artigo aponta que existem sinais, sintomas da violência, que são perceptíveis aos profissionais que assim estiverem atentos, o que ratifica a importância desse olhar atento.

As pesquisas de Soares et al. (2013) contribuem para as propostas de melhoria da rede de apoio social ao relatarem necessidade de intervenção em nível primário, com conversas com a população, buscando participação desta na temática e também nos serviços de saúde. Estes precisam vivenciar um trabalho em conjunto com escolas, família e comunidade

\section{Consideraçoes finais}

Ao analisarmos os artigos da Revisão Integrativa da Literatura, foram identificadas as seguintes questões frente à rede de apoio de adolescentes vítimas de violência: notórias falhas na rede assistencial, dificuldades no que tange a formação de vínculo entre as instituições, fragmentação dos serviços de assistência, falhas na comunicação, além de falta de recursos, escassez de preparo e qualificação profissional e alta demanda. Todos esses fatores, juntos, impedem que a rede de apoio social flua de modo mais eficaz.

Também foram percebidas lacunas da rede de apoio socioafetiva de adolescentes vítimas de violência, visto que, embora a família seja uma estrutura muito mencionada quanto às denúncias ou suporte para lidar com momentos difíceis tais como a violência, também existe uma precariedade de vínculos e poucos laços afetivos ou significativos nas pesquisas apontadas.

Percebeu-se também a necessidade da execução de um trabalho interdisciplinar para que haja uma ação efetiva e protetiva em rede; além da proposta de fortalecimento e melhoria da rede, com investimento em capacitação profissional, intervenções de caráter primário e secundário, melhor comunicação e interdisciplinaridade entre os setores responsáveis pela proteção de crianças e adolescentes.

Verificou-se a necessidade de cuidado do Estado frente aos equipamentos de proteção de crianças e adolescentes, visando melhor infraestrutura, capacitação profissional e também estruturação de um trabalho em rede fluido e efetivo.

Para finalizar, entendemos de forma peremptória que mais pesquisas interventivas no campo das famílias em situação de vulnerabilidade, proteção de crianças e adolescentes, bem com a comunidade e com as equipes que constroem a rede de apoio de crianças e adolescentes vítimas de violência, são necessárias e de fundamental importância para o pleno desenvolvimento de crianças e adolescentes acolhidos institucionalmente.

\section{Referências}

ABELSKY, Jay. Etiology of child maltreatment: A developmental-ecological analysis.

Psychology Bulletin, Washington, v. 114, n.3, p. 413-434, 1993

BRASIL. Estatuto da Criança e do Adolescente, Câmera dos Deputados, Lei no 8.069, de 13 de julho de 1990. DOU de 16/07/1990 - ECA. Brasília, DF.

BRASÍLIA. DF. Ministério da Saúde. Secretaria de Atenção à Saúde. Departamento de Ações Programáticas Estratégicas. Impacto da violência na saúde das crianças e adolescentes, 2010. Disponível em: https://crianca. mppr.mp.br/arquivos/File/publi/ms/cartilha_impacto_violencia.pdf. Acesso em: 03 dez. 2018.

BRONFENBRENNER, Urie. A ecologia do desenvolvimento humano. Porto Alegre: Artes Médicas, 1996. (Original publicado em 1979).

BRONFENBRENNER, Urie. Making human beings human: Bioecological perspectives on human developmental. Thousand Oaks, CA: Sage, 2004.

CARLOS, Diene et al. Violência doméstica contra crianças e adolescentes: olhares sobre a rede de apoio. Revista Gaúcha de Enfermagem., Rio Grande do Sul, n. 37, 2016. Disponível em: http://www.scielo.br/scielo. php?pid=S1983- $\quad 14472016000500426 \&$ script $=$ sci_abstract\&tlng=pt. Acesso em: 20 mai. 2019.

CECCONELlO, Alessandra et al. Práticas parentais e abuso físico no contexto familiar. Psicologia em Estudo, Paraná, v.8, p.45-54, 2003. 
Disponível em: https://www.scielo.br/pdf/pe/v8nspe/v8nesa07.pdf. Acesso em: 05 set. 2020

DE ANTONI; Clarissa; KOLLER, Silvia Helena. Uma família fisicamente violenta: uma visão pela teoria bioecológica do desenvolvimento humano. Temas psicol., São Paulo, v.18, n.1 Ribeirão Preto, 2010. Disponível em: http://pepsic.bvsalud.org/scielo.php?script=sci_arttext\&pid=S1413389X2010000100003. Acesso em: 01 dez. 2018.

ELOY, Consuelo. Violência intrafamiliar na infância: representações e realidades. In: MATTIOLI, Olga et al. Violência, direitos humanos e políticas públicas: avanços e impasses. Editora CRV: Curitiba, 2014, p. $105-117$.

FARAJ, Suzane; SIQUEIRA, Aline. O atendimento e a rede de proteção da criança e do adolescente vítima de violência sexual na perspectiva dos profissionais do CREAS. Barbarói, Santa Cruz do Sul, n.37, 2012. Disponível em: https://core.ac.uk/download/pdf/25776330.pdf. Acesso em: 20 mai. 2019

FERREIRA, Ana; SCHRAMM, Fermin. Implicações éticas da violência doméstica contra criança para profissionais de saúde. Revista de Saúde Pública, São Paulo, v. 34, n. 6, p. 659-665, 2000. Disponível em: https:// www.scielo.br/pdf/rsp/v34n6/3583.pdf. Acesso em: 05 set. 2020

GONÇALVES, Cláudia Fabiane et al. Atuação em rede no atendimento ao adolescente vítima de violência: desafios e possibilidades. Texto Contexto Enferm, Florianópolis, v.24, n.4, 2015. Disponível em: http://www.scielo. br/pdf/tce/v24n4/pt 0104-0707-tce- 201500004580014.pdf. Acesso em: 20 mai. 2019.

HABIGZANG, Luísa Fernanda; KOLLER, Silvia Helena, AZEVEDO, Gabriela et al. Abuso sexual infantil e dinâmica familiar: aspectos observados em processos jurídicos. Psicologia: teoria e pesquisa, Brasília, v.21, n.3, p.341-348, 2005. Disponível em: http://www.scielo.br/pdf/ptp/v21n3/ a11v21n3.pdf. Acesso em: 01 dez. 2018.

KHATTAR, Patrícia. Narrativas sobre deserção e reinserção familiar de crianças e adolescentes que habitaram a rua e a instituição de acolhimento. Dissertação de Mestrado apresantada ao Programa de Saúde Pública, na Faculdade de Saúde Pública da Universidade de São Paulo, para obtenção de título de Mestre em Saúde Pública. São Paulo, 2019. Disponível em: https://teses.usp.br/teses/disponiveis/6/6143/tde-04022020-162949/ptbr.php. Acesso em: 06. nov. 2019.

MAYER, Lísia. Rede de apoio social e representação mental das relações de apego de meninas vítimas de violência doméstica. Tese de doutorado em psicologia na Universidade Federal do Rio Grande do Sul, dezembro, 2002. Disponível em: https://www.lume.ufrgs.br/handle/10183/2793. Acesso em: 27 out. 2018 .

MAYER, Lísia; KOLLER, Silva Helena. Rede de apoio social e representação mental das relações de apego de crianças vítimas de violência doméstica. In: HABIGZANG, Luísa Fernanda et al. Violência contra crianças e adolescentes: teoria, pesquisa e prática. Porto Alegre: Artmed, 2012, p. 2132 .

MELO, Rosana et al. Cuidados de enfermagem à criança e adolescente em violência doméstica na visão de graduandos de enfermagem. Av Enferm. Bogotá, v.35, n.3, 2017. Disponível em: http://www.scielo.org.co/pdf/aven/ v35n3/0121-4500-aven-35-03- 00293.pdf. Acesso em: 20 mai. 2019.

NETO, Otávio; MOREIRA, Marcelo. A concretização de políticas públicas em direção à prevenção da violência estrutural. Ciênc. Saúde Coletiva, Rio de Janeiro, v. 4, n. 1, p.33-52, 1999. Disponível em: https:/www.scielo.br/ scielo.php?pid=S1413-81231999000100004\&script=sci_arttext. Acesso em: 06 fev. 2021.

PALUDO, Simone; SCHIRÒ, Eva. Um estudo sobre os fatores de risco e proteção associados à violência sexual cometida contra adolescentes e jovens adultos. Estudos de Psicologia, Campinas, v.17, n.3, 2012. Disponível em: $\quad$ http://www.scielo.br/scielo.php?script=sci_arttext\&pid=S1413294X2012000300007. Acesso em: 20 mai. 2019.

RIBEIRO, Leila Maria; LEITE, Ligia Maria. Violência doméstica, infância e rede de apoio. Rev. Latinoam. Psicopat. Fund., São Paulo, v. 21, n.3, p. 646-659, 2018. Disponível em: http://www.scielo.br/scielo.php?script=sci abstract\&pid=S1415- $\quad 47142018000300646 \& \operatorname{lng}=$ en\&nrm=iso\&tlng=pt. Acesso em: 20 mai. 2019.

SIQUEIRA, Aline et al. A rede de apoio social e afetivo de adolescentes institucionalizados no Sul do Brasil. Revista Interamericana de Psicologia, online, v.40, n.2, p.149-158, 2006. Disponível em: https://www.researchgate. net/publication/28293617_A_rede_de_apoio_social_e_afetivo_de adolescentes institucionalizados no sul do Brasil. Acesso em: $03 \mathrm{dez}$ 2018 .

SIQUEIRA, Aline, ABAID, Josiane, DELL'ALGIO, Débora. Famílias e instituições de acolhimento: interfaces entre risco e proteção. In: HABIGZANG, Luísa Fernanda et al. Violência contra crianças e adolescentes: teoria, pesquisa e prática. Porto Alegre: Artmed, 2012, p. 176190.

SOARES, Joannie et al. Violência nos relacionamentos afetivo-sexuais entre adolescentes de Porto Alegre, Rio Grande do Sul, Brasil: busca de ajuda e rede de apoio. Cad. Saúde Pública, online, v.29, n.6, 2013. Disponível em: http:// www.scielo.br/scielo.php?pid=S0102- 311 X2013000600009\&script=sci abstract\&tlng=pt. Acesso em: 20 mai. 2019

SOUZA, Marcela et al. Revisão integrativa: o que é e como fazer? Einstein, São Paulo, v. 8, n. 1, p. 102-106, 2010. Disponível em: https://journal. 45082010000100102/1679-4508- eins-S1679-45082010000100102-pt. x57660.pdf. Acesso em: 02 nov. 2018.

TEIXEIRA-FILHO, Fernando et al. Tipos e consequências da violência sexual sofrida por estudantes do interior paulista na infância e/ou adolescência. Psicologia \& Sociedade, online, v.25, n.1, 2013. Disponível em: http://www. scielo.br/scielo.php?script=sci arttext\&pid=S0102-71822013000100011. Acesso em: 20 mai. 2019.

UNESP. Tipos de revisão de literatura. Biblioteca Prof Paulo de Carvalho Matos, Faculdade de Ciências Agronômicas UNESP Campus Botucatu, 2015. Disponível em: http://www.fca.unesp.br/Home/Biblioteca/tipos-deevisao-de-literatura.pdf. Acesso em: 27 out. 2018.

UNICEF. Colóquio violências e seus impactos no desenvolvimento infantil: Reflexões históricas e contextuais, fatores de proteção e políticas públicas, 2015. Disponível em: http://primeirainfancia.org.br/wpcontent/ uploads/2015/06/Coloquio UNICEF web.pdf. Acesso em: 03 dez. 2018 


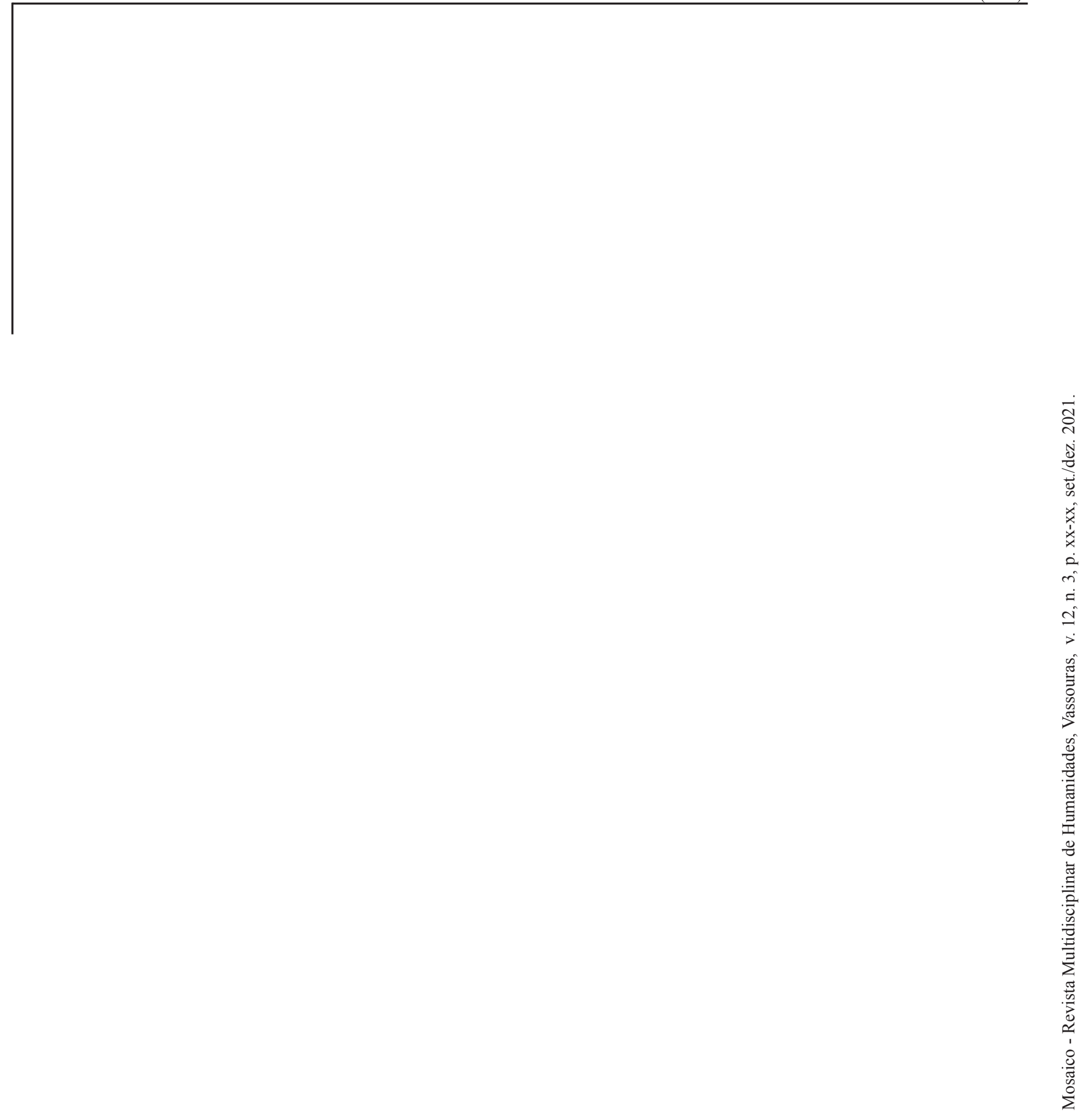

